\title{
Global incidence of oesophageal cancer by histological subtype in 2012
}

\author{
Melina Arnold, Isabelle Soerjomataram, Jacques Ferlay, David Forman
}

- Additional material is published online only. To view please visit the journal online (http://dx.doi.org/10.1136/ gutjnl-2014-308124).

Section of Cancer Surveillance, International Agency for Research on Cancer, Lyon, France

\section{Correspondence to}

Dr Melina Arnold, Section of Cancer Surveillance, International Agency for Research on Cancer, 150 Cours Albert Thomas, Lyon 69008, France; arnoldm@fellows.iarc.fr

Received 24 July 2014 Revised 26 August 2014 Accepted 28 August 2014 Published Online First 15 October 2014

\begin{abstract}
Objective The two major histological types of oesophageal cancer-adenocarcinoma (AC) and squamous cell carcinoma (SCC) - are known to differ greatly in terms of risk factors and epidemiology. To date, global incidence estimates for individual subtypes are still lacking. This study for the first time quantified the global burden of oesophageal cancer by histological subtype.
\end{abstract}

Design Where available, data from Cancer Incidence in Five Continents Vol. X (CI5X) were used to compute, age-specific, sex-specific and country-specific proportions of $A C$ and SCC. Nine regional averages were computed for countries without CI5X data. The proportions were then applied to all oesophageal cancer cases from GLOBOCAN 2012 and age-standardised incidence rates calculated for both histological types.

Results Worldwide, an estimated 398000 SCCs and 52000 ACs of the oesophagus occurred in 2012, translating to incidence rates of 5.2 and 0.7 per 100 000, respectively. Although SCCs were most common in South-Eastern and Central Asia (79\% of the total global SCC cases), the highest burden of $A C$ was found in Northern and Western Europe, Northern America and Oceania (46\% of the total global AC cases). Men had substantially higher incidence than women, especially in the case of $\mathrm{AC}$ (male to female ratio AC: 4.4; SCC: 2.7).

Conclusions These first global estimates of oesophageal cancer incidence by histology suggested a high concentration of $A C$ in high-income countries with men being at much greater risk. This quantification of incidence will aid health policy makers to plan appropriate cancer control measures in the future.

\section{INTRODUCTION}

Oesophageal cancer is the eighth most common cancer worldwide, with an estimated 456000 new cases and 400000 deaths in 2012. ${ }^{1}$ Around 80\% of all cases occurred in less-developed regions. The majority of oesophageal cancers can be subdivided into two main histological subtypes: adenocarcinomas (AC) and squamous cell carcinomas (SCC). Whereas ACs typically develop in the lower third of the oesophagus and originate predominantly from Barrett mucosa, SCC occurs mostly in flat cells lining the upper two-thirds of the oesophagus. ${ }^{2}$ High-grade dysplasia is the precursor for both types, while the development of AC can additionally be characterised by a progression from Barrett's metaplasia to dysplasia and ultimately invasive carcinoma.

\section{Significance of this study}

What is already known on this subject?

- The two main types of oesophageal cancer, squamous cell carcinoma (SCC) and adenocarcinoma (AC), differ greatly in their aetiology and epidemiology. To date, however, no global incidence estimates exist.

- While the incidence of $A C$ has been increasing in several high-income countries during the past years, trends in SCC have remained stable or have decreased.

\section{What are the new findings?}

- In this study, we quantified for the first time the global burden oesophageal cancer by histological type. In 2012, an estimated 398000 cases of SCC and 52000 cases of occurred globally.

- The incidence of SCC was highest in South-Eastern and Central Asia, where 79\% of all SCC cases occurred. In contrast, the burden of $A C$ was highest in Northern and Western Europe, Northern America and Oceania, which accounted for $46 \%$ of the global AC cases.

- While SCC is the more common type of oesophageal cancer on the global scale, incidence rates of $A C$ notably exceeded those of SCC in the Netherlands and in the UK. This was also true for New Zealand, the USA, Canada, Ireland, Iceland, Australia, Norway, Malta, Sweden, Bahrain and Cyprus.

- For both sites, men had substantially higher incidence than women. This was more pronounced for $A C$, where incidence in men was on average four times greater than in women and over eight times greater in Northern America.

How might it impact on clinical practice in the foreseeable future?

- This quantification of incidence accords with aetiological research and will aid health policy makers to plan appropriate cancer control measures in the future.

The two subtypes differ greatly in terms of their male to female ratio, risk factors and incidence patterns across countries. ${ }^{2-4}$ In recent decades, enigmatic increases in the incidence of oesophageal AC have been observed among white populations in

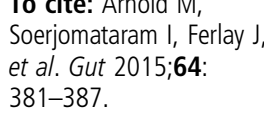


high-income countries. ${ }^{5}$ This increase has largely been attributed to the rising prevalence of obesity, although some controversy exists around this hypothesis. In contrast, the declining incidence of SCC in more developed regions roughly mirrors the decline in tobacco smoking, one of the most important risk factors for SCC. ${ }^{3}$ SCC remains most common in less-developed regions of the world, including Africa ${ }^{6-8}$ and Eastern Asia. ${ }^{9}$ The reasons for this are not yet entirely understood.

Although overall global and country-specific incidence estimates of oesophageal cancer have been available through the GLOBOCAN project since $1990,{ }^{10-13}$ breakdown by histological subtype has not been possible. Here, for the first time, we estimate the global, regional-specific and country-specific incidence of oesophageal cancer by histological type, based on data from Cancer Incidence in Five Continents Vol. X (CI5X) ${ }^{14}$ and GLOBOCAN 2012. ${ }^{1}$

\section{MATERIAL AND METHODS}

The estimated total numbers of oesophageal cancers in 2012 by age, sex and country were obtained from GLOBOCAN 2012. ${ }^{1}$ For each country, we estimated the age-specific and sex-specific number of SCC and AC cases by multiplying the estimated number of oesophageal cancer cases in 2012 by the respective proportions of each histological subtype from relevant cancer registry data extracted from $\mathrm{CI} 5 \mathrm{X}^{14}$ using one of two methods.

Sex-specific and age-specific ( $<65$ and $\geq 65$ years) proportions of AC and SCC were computed for all countries included in CI5X except for those with no cases of either AC or SCC in one of our four substrata (men and women $<65$ and $\geq 65$ years). Where data were available from multiple regional registries within a country, cases and populations were pooled to obtain national proportions. The sum of all carcinomas (AC +SCC+other carcinomas) was used as the denominator. The histological types were defined according to the third edition of the International Classification of Diseases for Oncology (ICD-O-3) which were presented in Cancer Incidence in Five Continents Vol. IX (CI5IX) ${ }^{15}{ }^{16}$; SCCs: $8050-8078$ and 80838084; ACs: 8140-8141, 8143-8145, 8190-8231, 8260-8263, $8310,8401,8480-8490,8550-8551$ and 8570-8574, 8576. Other histological subtypes, such as sarcomas, were found to constitute $<1 \%$ of all oesophageal cancer cases and were considered negligible. Using this approach, country-specific proportions could be computed for 57 countries.

For the remaining 127 countries without data in CI5X or with zero cases in a substratum, proportions were calculated for nine broad regions. The data for each region were derived from CI5X and were complemented with data from CI5IX ${ }^{16}$ and from the African Cancer Registry Network (AFCRN) for the sub-Saharan African region. Regions are based on the following UN geographical regions ${ }^{17}$ : sub-Saharan Africa (including Eastern, Middle, Southern and Western Africa), Northern Africa and Western Asia, Central Asia (including India), Eastern and South-Eastern Asia (including China), Latin America and the Caribbean, Eastern Europe, Northern and Western Europe, Southern Europe and Oceania.

Age-standardised incidence rates (per 100000 person-years) were calculated for each country and region and according to the four categories of human development index (HDI) in $2012^{18}$ using the direct method and the World Standard Population. $^{19}$

\section{RESULTS}

In 2012, an estimated 456000 men and women developed oesophageal cancer, of which 398000 cases were SCCs
(278 000 in men, 120000 in women), 52000 were ACs (41000 in men, 11000 in women) and 6000 other carcinomas. In more than $90 \%$ of all countries presented in GLOBOCAN 2012, the rate of oesophageal SCC for both sexes combined clearly exceeded that of AC. In contrast, a few countries had higher rates of AC than of SCC, which was most pronounced in the Netherlands and in the UK but was also true for New Zealand, the USA, Canada, Ireland, Iceland, Australia, Norway, Malta, Sweden, Bahrain and Cyprus.

\section{Oesophageal AC}

The global incidence of oesophageal AC was 0.7 per 100000 (1.1 in men and 0.3 in women) and varied greatly across countries (figures 1 and 2). While the highest incidence rates were found in Northern and Western Europe, Northern America and Oceania (figure 3 ; see online supplementary annex table 1), the regions with the lowest rates were Eastern and South-Eastern Asia and sub-Saharan Africa. On a national level, the highest rates were observed in the UK (7.2 in men and 2.5 in women), The Netherlands (7.1 in men and 2.8 in women), Ireland (5.4 in men and 2.9 in women), Iceland (3.9 in men and 2.7 in women) and New Zealand (4.0 in men and 1.5 in women; see online supplementary annex table 2 for the full list of estimates by sex and country). A gradient was found across HDI regions for men with the highest rates observed in very high HDI countries (2.3 in men and 0.3 in women) and the lowest incidence in low HDI countries ( 0.6 in men and 0.3 in women; figure 4).

Overall, AC rates were substantially higher in men than in women. The male to female ratio was 4.4 , ranging from 1.7 in sub-Saharan Africa to 8.5 in Northern America.

In absolute terms, most cases of AC occurred in Northern and Western Europe $(22.8 \%, 12000$ cases), followed by South-East Asia (including China; 21.9\%, 11500 cases) and Northern America (21.2\%, 11100 cases; figure 5). At the country level, most cases occurred in the US (10 000 cases), of which $88 \%$ were in men.

\section{Oesophageal SCC}

In 2012, the global incidence of oesophageal SCC was 5.2 per 100000 (7.7 in men and 2.8 in women). The most affected region was Eastern and South-East Asia with rates of 13.6 per 100000 in men and 4.3 in women, followed by sub-Saharan Africa and Central Asia (figures 1-3; see online supplementary annex table 1). The highest estimated national rates were those of Malawi, Turkmenistan, Kenya, Mongolia and Uganda (see online supplementary annex table 2). Excluding China, the highest rates were found in low HDI countries for both men and women (6.9 and 4.6, respectively) and rates were lower for all other HDI categories (figure 4).

In general, rates in men exceeded those of women. While the global male to female ratio of oesophageal SCC was 2.7, it was highest in Eastern Europe (7.8) and lowest in Northern Africa and Western Asia (1.2).

About $80 \%$ of the global oesophageal SCC cases occurred in the Central and South-East Asian region, corresponding to 315000 cases. China alone contributed more than half of the global cases (53\%, 210000 cases). Of the remaining regions, sub-Saharan Africa $(5.7 \%, 13000$ cases) and Central and Southern America (4.1\%, 12000 cases) carried the highest absolute burden of oesophageal SCC in 2012.

\section{DISCUSSION}

In this study, we have quantified, for the first time, the global burden of oesophageal cancer and its geographical variation by 


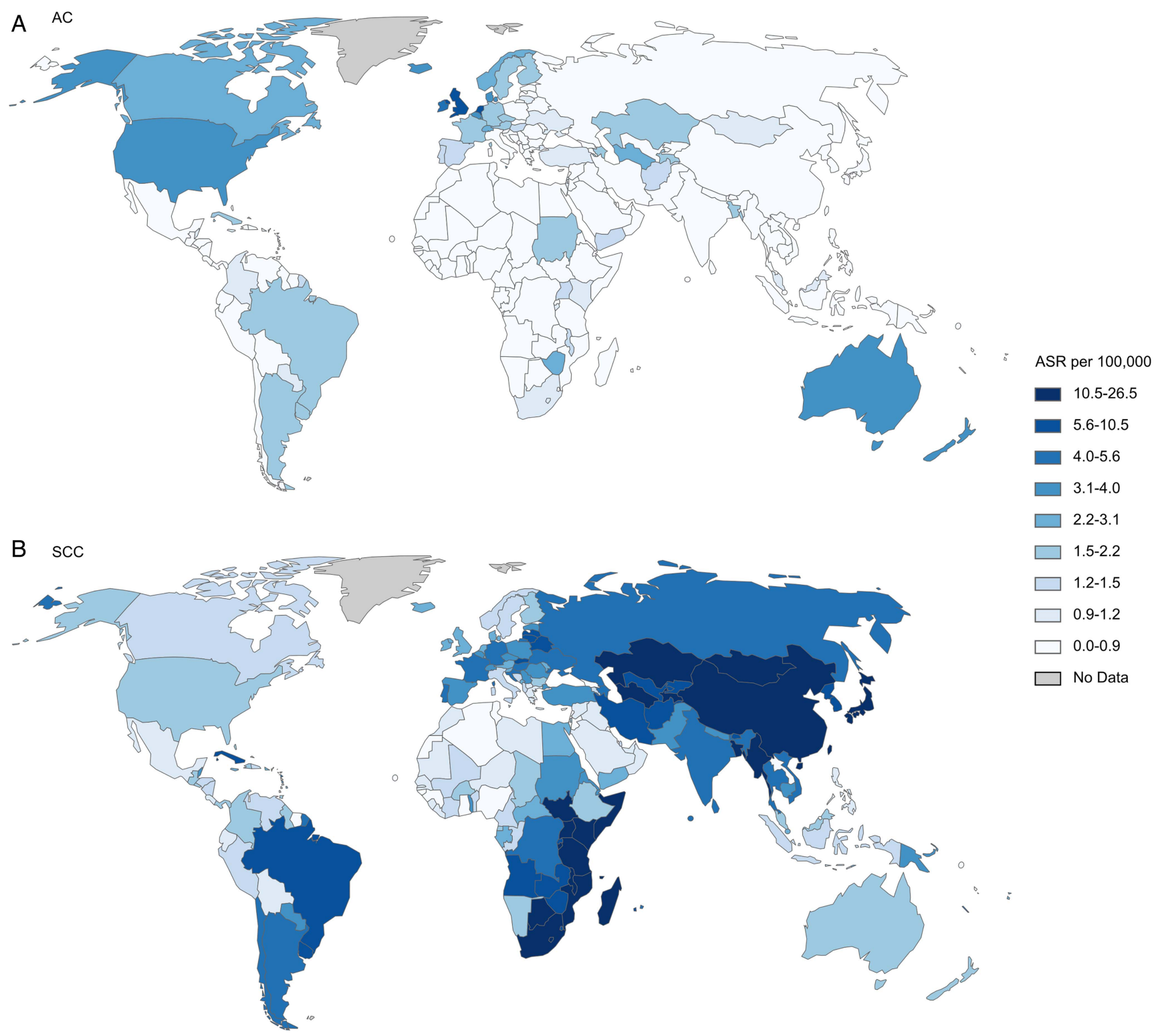

Figure 1 Age-standardised incidence rate (ASR) per 100000 of (A) oesophageal adenocarcinoma and (B) squamous cell carcinoma in men. $A C$, adenocarcinoma; SCC, squamous cell carcinoma.

histological subtype. While the incidence of SCC-the more common subtype globally - was highest in South-Eastern Asia, AC predominated in Northern and Western Europe and also in Northern America and Oceania. For both subtypes, but particularly AC, men had substantially higher incidence of oesophageal cancer than women.

These results largely support the findings of previous studies. High incidence areas of oesophageal SCC have been identified in Northern Iran, ${ }^{4}$ Central Asia and China ${ }^{9}$ (together forming the so-called 'oesophageal cancer belt') as well as parts of Eastern Africa. ${ }^{6} 820$ This pattern was also reflected in our results, where high rates of oesophageal SCC were mainly confined to those regions. In contrast, the incidence of oesophageal $\mathrm{AC}$ was greatest in high-income countries such as the US and the UK, where incidence has increased substantially in recent decades. ${ }^{3}$ Changing patterns in the epidemiology of the two types were also confirmed in countries where historically SCC was the predominant type of oesophageal cancer and $\mathrm{AC}$ is now on the rise. This was, for example, the case in $\operatorname{Iran}^{21}$ where rates of AC, especially in women, were among the highest in the Central Asian region.

In general, chronic irritation and inflammation of the oesophageal mucosa have been postulated to increase the risk of oesophageal SCC. The two strongest risk factors are smoking and alcohol consumption, which have been found to account for more than $75 \%$ of all SCC cases in high-income countries. ${ }^{22}{ }^{23}$ Frequent consumption of extremely hot beverages is common risk factor for oesophageal SCC in less-developed regions. While for instance in Latin America, hot mate drinking has been shown to double the risk of oesophageal SCC, ${ }^{24}$ the consumption of very hot beverages was associated with a ninefold increase in risk in Southern China. ${ }^{25}$ In the latter study, high-temperature cooking methods, including barbecuing and frying, were also found to increase the risk for oesophageal cancer. In Iran, opium use has been found to increase mortality from oesophageal cancer by $50 \%{ }^{26}$ Also, low socioeconomic status, poverty and poor oral hygiene have been linked to an increased risk of oesophageal SCC. ${ }^{23} 2728$ Studies from 


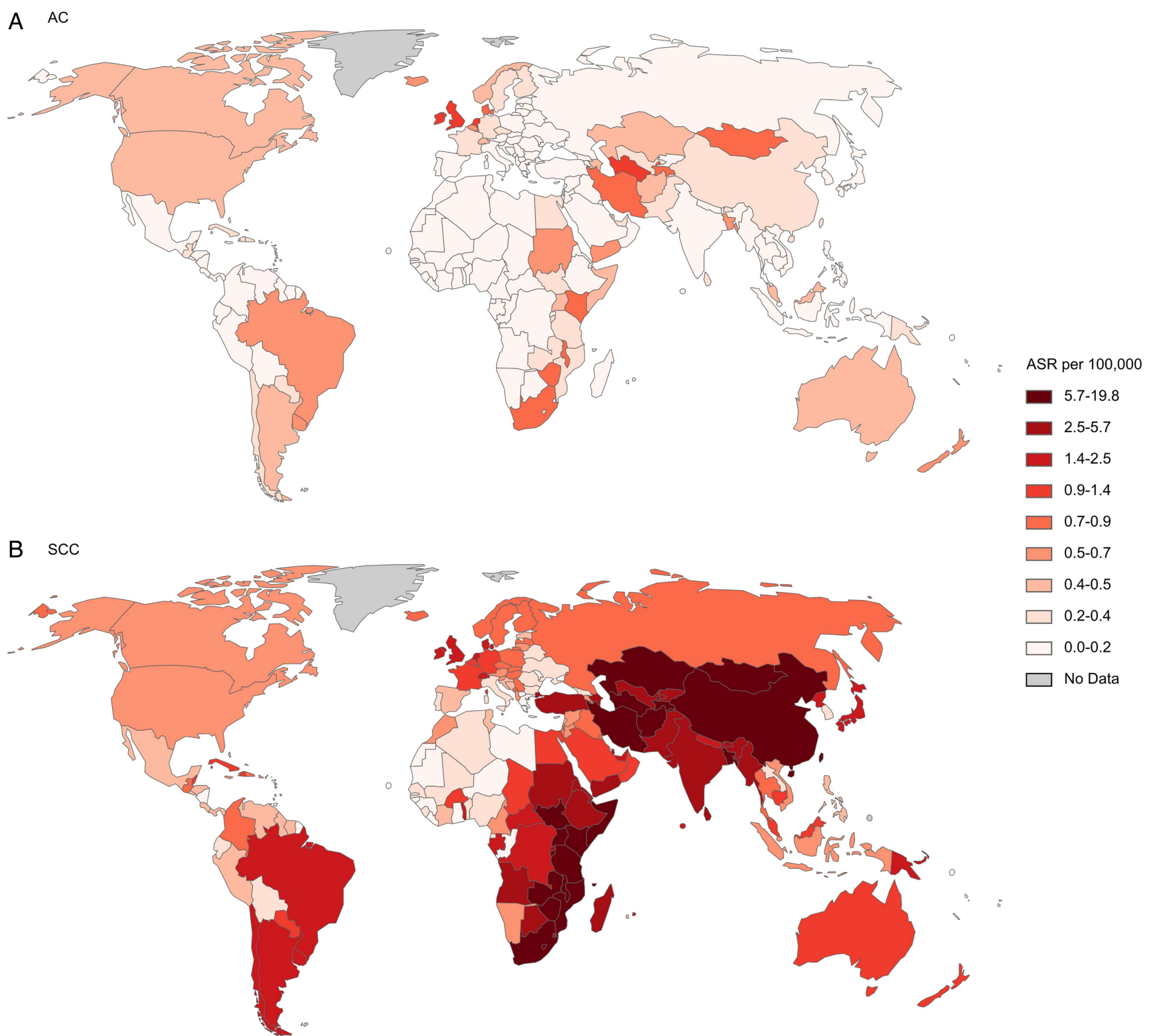

Figure 2 Age-standardised incidence rate (ASR) per 100000 of (A) oesophageal adenocarcinoma and (B) squamous cell carcinoma in women. $\mathrm{AC}$, adenocarcinoma; SCC, squamous cell carcinoma.

high-incidence areas in Africa have suggested that smoking, occupational exposures and nutritional deficiencies may be responsible for the high burden of oesophageal SCC in that region. 62029

The strongest known risk factor for oesophageal AC is gastrooesophageal reflux disease, alongside its more severe manifestation, Barrett's oesophagus. ${ }^{30} 31$ In more recent years, prevalence of the latter has reached a plateau in high-prevalence countries such as the Netherlands and the UK. ${ }^{32}$ Given a lag time of about 10 years between the onset of Barrett's oesophagus and progression to severe dysplasia, ${ }^{33}$ the high and potentially rising incidence of oesophageal AC may also slowdown in these areas. Although obesity promotes the development of gastrooesophageal reflux and also acts as an independent risk factor for oesophageal AC, ${ }^{34} 35$ obesity trends do not seem to be entirely concordant with the trends seen for oesophageal AC. ${ }^{5} 36$ Recent evidence has suggested a possible role of Helicobacter pylori ( $\mathrm{H}$ pylori) in the increasing rates of oesophageal AC. ${ }^{37}$ $H$ pylori lowers gastric acid secretion, hence gastric oesophageal reflux. Its declining prevalence in many Western countries ${ }^{38}$ may have led to higher levels of gastric acidity and therefore higher incidence of oesophageal AC. This could, in part, explain the high incidence observed in Northern America and Northern and Western Europe, where the prevalence of $H$ pylori infection is among the lowest in the world. Similarly, there seems to be an inverse association between $H$ pylori infection and the prevalence of overweight, ${ }^{39}$ meaning that gradual decreases in $H$ pylori prevalence could be related to the obesity epidemic - a major risk factor of oesophageal AC.

The marked sex difference in the incidence of oesophageal AC and its geographical variation have been discussed previously ${ }^{41}$ and still remain to be elucidated, as none of the above-described risk factors offer a complete explanation for this disparity. Sex hormones have been suggested to offer protection against this tumour in women; breast feeding, for instance, has been shown to decrease the risk for oesophageal $\mathrm{AC}$ in women. ${ }^{42}$ Also, altered levels of adipokines such as leptin produced by visceral adipose tissue, which is more often observed in men, have been 


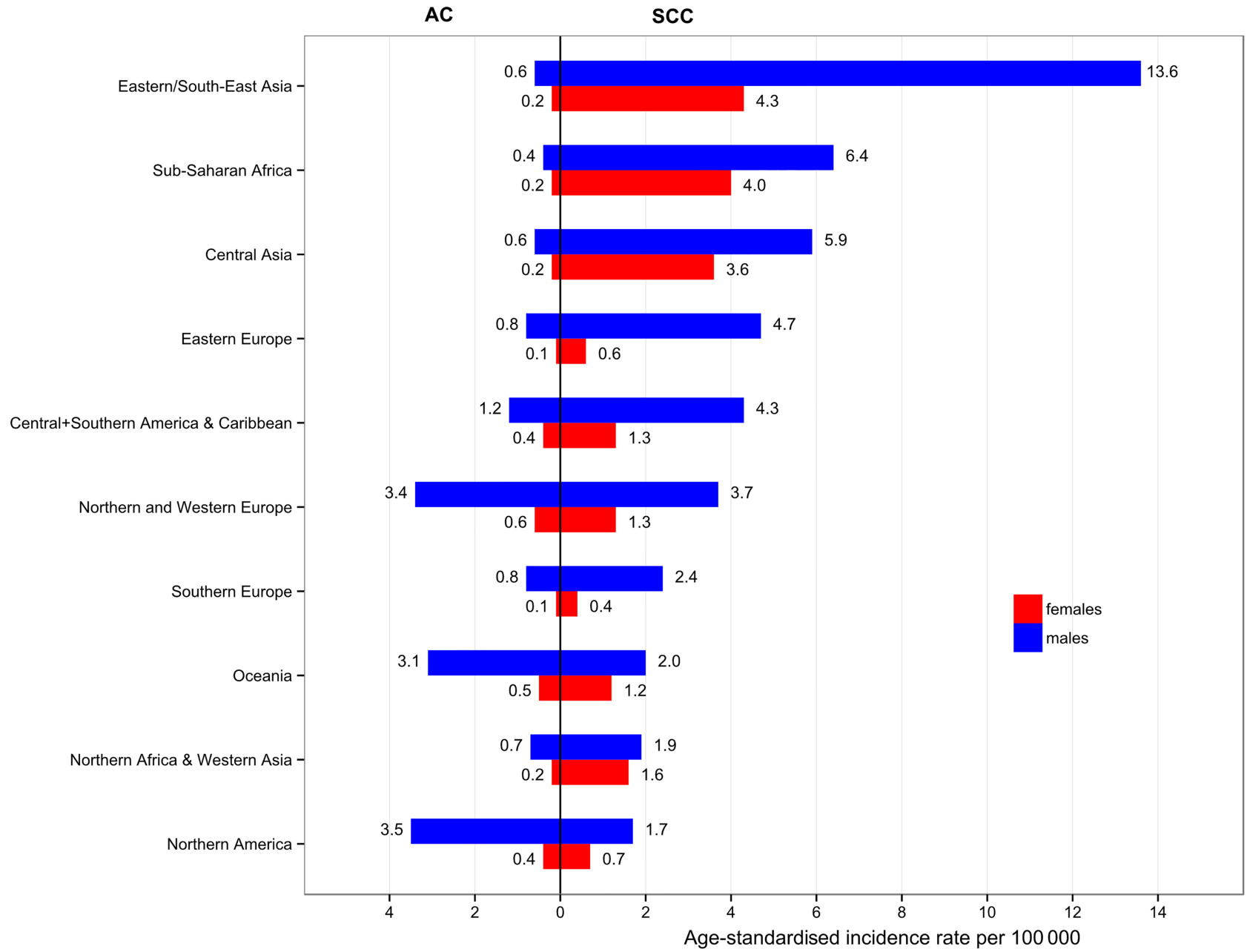

Figure 3 Age-standardised incidence rate per 100000 of oesophageal cancer by histological subtype, region and sex. AC, adenocarcinoma; SCC, squamous cell carcinoma.

suggested to contribute to markedly differential incidence of AC by sex. ${ }^{43}$ This has been supported by the observation that patients with Barrett's oesophagus have a greater waist circumference than population controls, even within strata of body mass index. $^{44}$

To date, no national screening programmes for oesophageal cancer exist. Since incidence in most countries is low, costs for screening (using endoscopy) are relatively high and risk of complications is substantial, experts refrain from recommending larger-scale oesophageal cancer screening. ${ }^{45} 46$ Screening for preinvasive stages, for example, Barrett's oesophagus for AC, should target high-risk patients with chronic gastro-oesophageal reflux disease and multiple risk factors, that is, older age, male sex, obesity and family history. ${ }^{45}$ In high-risk regions such as
Figure 4 Age-standardised incidence rate per 100000 of oesophageal cancer by histological subtype, HDI and sex (excluding China). AC, adenocarcinoma; SCC, squamous cell carcinoma; HDI, human development index.

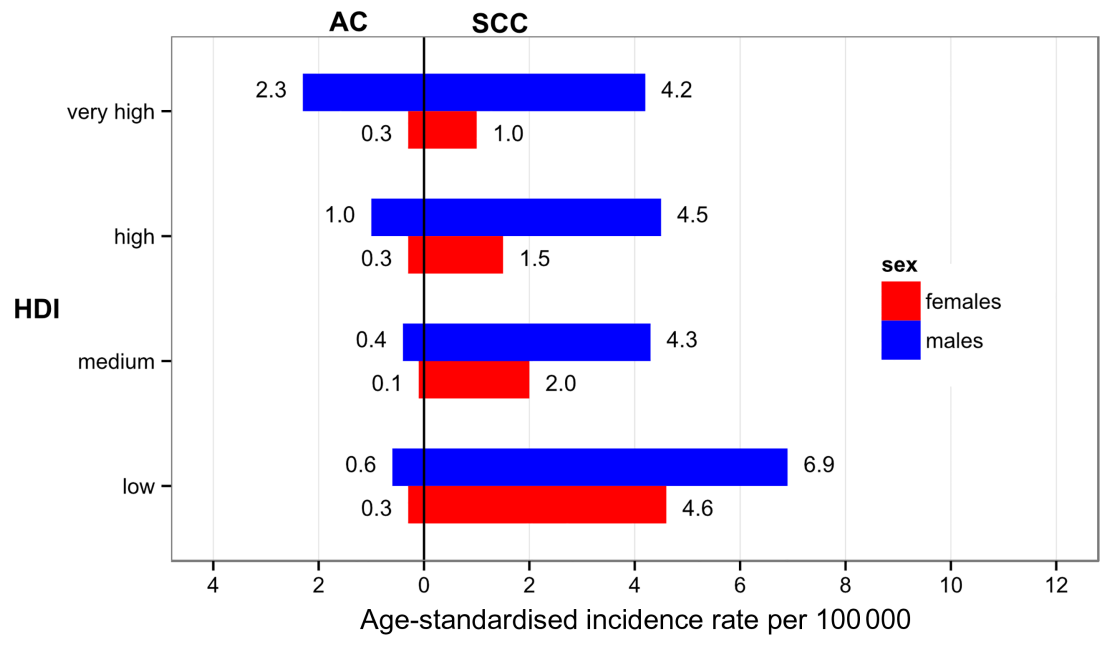


Figure 5 Regional distribution of estimated oesophageal cancer cases by histological subtype in 2012. CA, Central Asia; EE, Eastern Europe; LAC, Central \& Southern America and Caribbean; NAm, Northern America; NAf \& WA, Northern Africa/Western Asia; NWE, North Western Europe; OC, Oceania; SE, Southern Europe; SEA, South-East Asia; SSA, Sub-Saharan Africa.

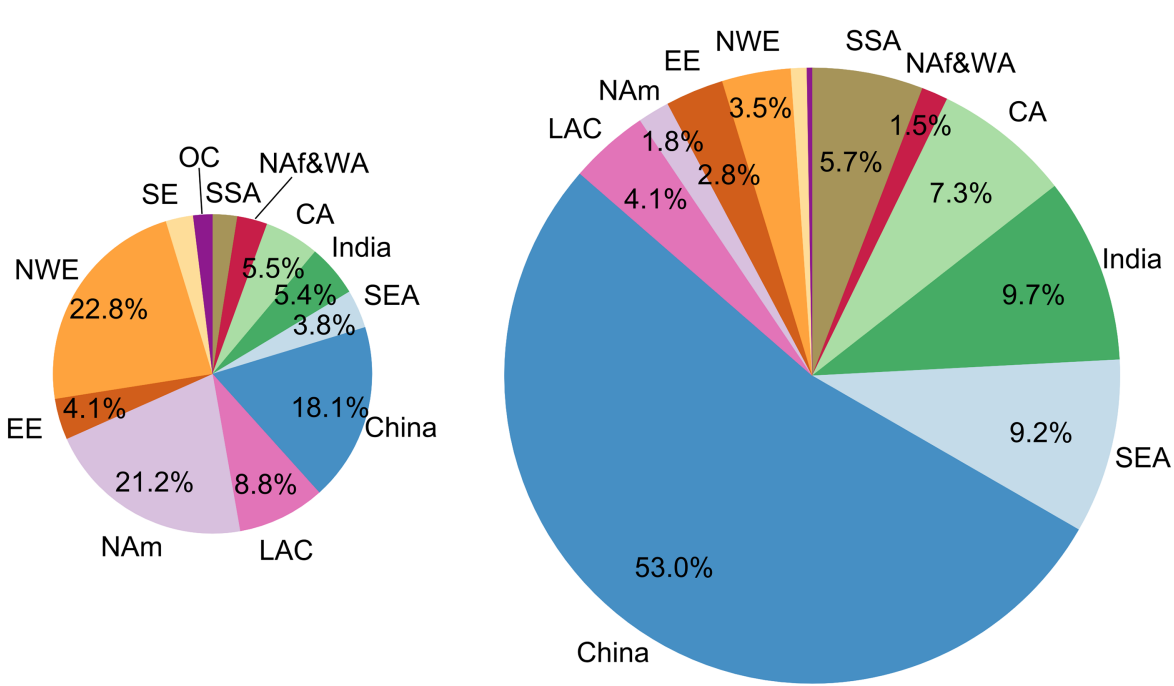

Squamous Cell Carcinoma 398000 estimated cases
Northern Iran and China, screening of asymptomatic adults using endoscopy has yielded rather low detection rates, suggesting the need for other screening methods and more accurate risk stratification. ${ }^{47}{ }^{48}$ Other, non-endoscopic screening methods and surveillance modalities including inflatable balloons and sponges have been developed but have remained unsuccessful due to their lack of sensitivity. ${ }^{46}$

To ensure the validity of our approach, we used only highquality data from cancer registries included in CI5X to compute proportions, and subsequently incidence rates, of oesophageal $\mathrm{AC}$ and SCC. Setting a minimum number of cases per registry led to the exclusion of mainly African registries, where there were in general very few AC cases. For countries without data in CI5X, regional proportions were computed using a comprehensive set of data from CI5 Vols. IX-X and from the AFCRN. Using regional proportions disregards any heterogeneity across countries within the regions, for example, in the case of the sub-Saharan African and Central Asian region, where data came from only a very limited number of cancer registries with sufficient cases and data quality. However, in agreement with previous reports, SCC accounted for over $90 \%$ of all oesophageal cancer cases in many sub-Saharan African countries ${ }^{6-8}$ and confirmed the high burden of this subtype in the Eastern part of the continent.

It is also important to note that GLOBOCAN itself represents incidence estimates that are based on the best data available but nevertheless need to be interpreted with caution, especially for countries where estimates are based on poor, insufficient or proxy data. Applying proportions to the estimates of those countries adds an additional layer of uncertainty around the true incidence figures. Furthermore, it is possible that misclassification has affected our results. This is rather unlikely in the case of SCC because its histological appearance is quite distinct from that of AC. However, misclassification of cancers of the gastrooesophageal junction could have led to an underestimation of the incidence of oesophageal AC. ${ }^{37} 49$

Despite the limitations above, estimating the global and country-specific burden of oesophageal cancer by histological subtype remains of great importance for future cancer control strategies. As mortality data, that is, basic death certification information, are less specific than incidence data coming from registration and do not provide any indication of histological subtype, this work was not repeated for other cancer indicators. Yet, since oesophageal cancer is often fatal, with 5 -year survival rates of 19\% (2003-2009) in the USA ${ }^{50}$ and 12\% (2000-2007) in Europe ${ }^{51}$ mortality and incidence patterns are likely to be very similar.

\section{CONCLUSION}

While the incidence of SCC was highest in South-Eastern Asia, Eastern Africa and Latin America, AC predominated-sometimes even exceeding SCC-in Northern and Western Europe, Northern America and Oceania. Overall, these data support previous findings in relation to the prevalence and geographical variation of the respective subtypes. Yet, no comprehensive explanation for high rates of SCC in some areas, for example, Eastern Africa, exists based on currently known risk factors and requires further research. This quantification of incidence will aid health policy makers to plan appropriate cancer control measures.

Acknowledgements We would like to thank the African Cancer Registry Network (AFCRN) and all its collaborators for the provision of data. Furthermore, we would like to extend our thanks to Dr Valerie McCormack for her input on oesophageal cancer in the sub-Saharan African region.

Contributors MA, IS and DF contributed to study concept and design; all authors contributed in analysis and interpretation of data; MA and IS in drafting the manuscript and all authors contributed in critical revision of the manuscript for important intellectual content.

Funding MA has been supported by the World Cancer Research Fund, grant number SG 2012/619.

Competing interests None.

Provenance and peer review Not commissioned; externally peer reviewed.

\section{REFERENCES}

1 Ferlay J, Soerjomataram I, Ervik M, et al. GLOBOCAN 2012 v1.0, Cancer Incidence and Mortality Worldwide: IARC CancerBase No. 11. Lyon, France: International Agency for Research on Cancer, 2013.

2 Enzinger PC, Mayer RJ. Esophageal cancer. N Engl J Med 2003:349:2241-52.

3 Cook MB, Chow WH, Devesa SS. Oesophageal cancer incidence in the United States by race, sex, and histologic type, 1977-2005. Br J Cancer 2009;101:855-9.

4 Mosavi-Jarrahi A, Mohagheghi MA. Epidemiology of esophageal cancer in the high-risk population of Iran. Asian Pac J Cancer Prev 2006;7:375-80.

5 Edgren G, Adami HO, Weiderpass E, et al. A global assessment of the oesophageal adenocarcinoma epidemic. Gut 2013;62:1406-14

6 Ocama P, Kagimu MM, Odida M, et al. Factors associated with carcinoma of the oesophagus at Mulago Hospital, Uganda. Afr Health Sci 2008;8:80-4. 
7 White RE, Parker RK, Fitzwater JW, et al. Stents as sole therapy for oesophageal cancer: a prospective analysis of outcomes after placement. Lancet Oncol 2009;10:240-6.

8 Somdyala NI, Bradshaw D, Gelderblom WC, et al. Cancer incidence in a rural population of South Africa, 1998-2002. Int J Cancer 2010;127:2420-9.

9 Lin Y, Totsuka Y, He Y, et al. Epidemiology of esophageal cancer in Japan and China. J Epidemiol 2013;23:233-42.

10 Ferlay J, Parkin DM, Pisani P. GLOBOCAN. Cancer Incidence and Mortality Worldwide: IARC CancerBase No. 3. Lyon, France: International Agency for Research on Cancer, 1998

11 Ferlay J, Bray F, Pisani P, et al. GLOBOCAN 2000. Cancer Incidence, Mortality and Prevalence Worldwide: IARC CancerBase No. 5. Lyon, France: International Agency for Research on Cancer, 2001.

12 Ferlay J, Bray F, Pisani P, et al. GLOBOCAN 2002. Cancer Incidence, Mortality and Prevalence Worldwide: IARC CancerBase No. 5 version 2.0. Lyon, France: International Agency for Research on Cancer, 2004.

13 Ferlay J, Shin HR, Bray F, et al. Estimates of worldwide burden of cancer in 2008: GLOBOCAN 2008. Int J Cancer 2010;127:2893-917.

14 Forman D, Brewster DH, Gombe Mbalawa C, et al. Cancer incidence in five continents, Vol. X (electronic version). Lyon: IARC, 2013.

15 World Health Organization. International Classification of Diseases for Oncology. 3rd edn, First Revision. Geneva, Switzerland: World Health Organization, 2013.

16 Curado MP, Edwards B, Shin HR, et al. Cancer incidence in five continents, Vol. IX. Lyon, France: International Agency for Research on Cancer, 2007.

17 World Population Prospects. The 2012 Revision. New York: United Nations, Department of Economic and Social Affairs, Population Division, 2013.

18 Human Development Report 2013. The Rise of the South: Human Progress in a Diverse World. New York: United Nations Development Programme (UNDP), 2013.

19 Segi M. Cancer mortality for selected sites in 24 countries (1950-57). Sendai, Japan: Department of Public Health, Tohoku University of Medicine, 1960.

20 Vizcaino AP, Parkin DM, Skinner ME. Risk factors associated with oesophageal cancer in Bulawayo, Zimbabwe. Br J Cancer 1995;72:769-73.

21 Ghasemi-Kebria F, Roshandel G, Semnani S, et al. Marked increase in the incidence rate of esophageal adenocarcinoma in a high-risk area for esophageal cancer. Arch Iran Med 2013;16:320-3.

22 Pandeya N, Olsen CM, Whiteman DC. Sex differences in the proportion of esophageal squamous cell carcinoma cases attributable to tobacco smoking and alcohol consumption. Cancer Epidemiol 2013;37:579-84.

23 Brown LM, Hoover R, Silverman D, et al. Excess incidence of squamous cell esophageal cancer among US Black men: role of social class and other risk factors. Am J Epidemiol 2001;153:114-22

24 De Stefani $\mathrm{E}$, Deneo-Pellegrini $\mathrm{H}$, Ronco AL, et al. Diet patterns and risk of squamous cell oesophageal carcinoma: a case-control study in Uruguay. Asian Pac Cancer Prev 2014;15:2765-9.

25 Lin J, Zeng R, Cao W, et al. Hot beverage and food intake and esophageal cancer in southern China. Asian Pac J Cancer Prev 2011;12:2189-92.

26 Malekzadeh MM, Khademi H, Pourshams A, et al. Opium use and risk of mortality from digestive diseases: a prospective cohort study. Am J Gastroenterol 2013;108:1757-65.

27 Dar NA, Islami F, Bhat GA, et al. Poor oral hygiene and risk of esophageal squamous cell carcinoma in Kashmir. Br J Cancer 2013;109:1367-72.

28 Tran GD, Sun XD, Abnet CC, et al. Prospective study of risk factors for esophageal and gastric cancers in the Linxian general population trial cohort in China. Int J Cancer 2005; 113:456-63.

29 van Rensburg SJ, Benade AS, Rose EF, et al. Nutritional status of African populations predisposed to esophageal cancer. Nutr Cancer 1983;4:206-16.
30 Lagergren J, Bergstrom R, Lindgren A, et al. Symptomatic gastroesophageal reflux as a risk factor for esophageal adenocarcinoma. N Engl J Med 1999;340:825-31.

31 Hvid-Jensen F, Pedersen L, Drewes AM, et al. Incidence of adenocarcinoma among patients with Barrett's esophagus. N Engl J Med 2011;365:1375-83.

32 Masclee GM, Coloma PM, de Wilde M, et al. The incidence of Barrett's oesophagus and oesophageal adenocarcinoma in the United Kingdom and the Netherlands is levelling off. Aliment Pharmacol Ther 2014;39:1321-30.

33 Umar A, Dunn BK, Greenwald P. Future directions in cancer prevention. Nat Rev Cancer 2012;12:835-48.

34 Lagergren J. Influence of obesity on the risk of esophageal disorders. Nat Rev Gastroenterol Hepatol 2011;8:340-7.

35 Hoyo C, Cook MB, Kamangar F, et al. Body mass index in relation to oesophageal and oesophagogastric junction adenocarcinomas: a pooled analysis from the International BEACON Consortium. Int J Epidemiol 2012;41:1706-18.

36 Kroep S, Lansdorp-Vogelaar I, Rubenstein JH, et al. Comparing trends in esophagea adenocarcinoma incidence and lifestyle factors between the United States, Spain, and the Netherlands. Am J Gastroenterol 2014;109:336-43; quiz 5, 44.

$37 \mathrm{McColl} \mathrm{KE}$, Going JJ. Aetiology and classification of adenocarcinoma of the gastro-oesophageal junction/cardia. Gut 2010;59:282-4.

38 Khalifa MM, Sharaf RR, Aziz RK. Helicobacter pylori: a poor man's gut pathogen? Gut Pathog 2010;2:2.

39 Lender N, Talley NJ, Enck P, et al. Review article: associations between Helicobacter pylori and obesity —an ecological study. Aliment Pharmacol Ther 2014;40:24-31.

40 Lane JA, Murray L, Harvey IM, et al. Randomised clinical trial: Helicobacter pylori eradication is associated with a significantly increased body mass index in a placebo-controlled study. Aliment Pharmacol Ther 2011:33:922-9.

41 Cook MB, Wild CP, Forman D. A systematic review and meta-analysis of the sex ratio for Barrett's esophagus, erosive reflux disease, and nonerosive reflux disease. Am J Epidemiol 2005;162:1050-61.

42 Cronin-Fenton DP, Murray LJ, Whiteman DC, et al. Reproductive and sex hormonal factors and oesophageal and gastric junction adenocarcinoma: a pooled analysis. Eur J Cancer 2010;46:2067-76.

43 Chen Q, Zhuang H, Liu Y. The association between obesity factor and esophageal caner. J Gastrointest Oncol 2012;3:226-31.

44 Kubo A, Cook MB, Shaheen NJ, et al. Sex-specific associations between body mass index, waist circumference and the risk of Barrett's oesophagus: a pooled analysis from the international BEACON consortium. Gut 2013;62:1684-91.

45 Fitzgerald RC, di Pietro M, Ragunath K, et al. British Society of Gastroenterology guidelines on the diagnosis and management of Barrett's oesophagus. Gut 2014;63:7-42.

46 Lao-Sirieix P, Fitzgerald RC. Screening for oesophageal cancer. Nat Rev Clin Oncol 2012:9:278-87.

47 Lu XJ, Chen ZF, Guo CL, et al. Endoscopic survey of esophageal cancer in a high-risk area of China. World J Gastroenterol 2004;10:2931-5.

48 Roshandel G, Khoshnia M, Sotoudeh M, et al. Endoscopic screening for precancerous lesions of the esophagus in a high risk area in Northern Iran. Arch Iran Med 2014;17:246-52

49 Lindblad M, Ye W, Lindgren A, et al. Disparities in the classification of esophageal and cardia adenocarcinomas and their influence on reported incidence rates. Ann Surg 2006;243:479-85.

50 Siegel R, Ma J, Zou Z, et al. Cancer statistics, 2014. CA Cancer J Clin 2014:64:9-29.

51 De Angelis R, Sant M, Coleman MP, et al. Cancer survival in Europe 1999-2007 by country and age: results of EUROCARE-5-a population-based study. Lancet Oncol 2014:15:23-34. 